\title{
COLLECTIVE BARGAINING UNDER COMPLETE INFORMATION ${ }^{\star}$
}

\author{
by \\ Carlos Díaz-Moreno \\ University of Minnesota \\ and \\ José E. Galdón-Sánchez \\ London School of Economics and Political Science
}

Contents:

Abstract

1. Introduction

2. Collective Bargaining in Spain

3. The Model

4. The Data

5. Econometric Specification

6. Results

7. Conclusions

References

Tables $1-4$

Figures 1-7

Discussion Paper

No. TE/00/401

July 2000
The Suntory Centre

Suntory and Toyota International Centres for Economics and Related Disciplines London School of Economics and Political Science

Houghton Street

London WC2A $2 \mathrm{AE}$

Tel.: 02074057686

\footnotetext{
* We thank Alfonso Alba for providing us with the data set. José E. Gáldon thanks the European Commission for a TMR Marie Curie Fellowship.
} 


\begin{abstract}
In this paper, we build and structurally estimate a complete information bargaining model of collective negotiation for Spain. For large firms, the assumption of complete information seems a sensible one, and it matches the collective bargaining environment better than the one provided by private information models. The specification of the model with players having different discount factors allows us to measure their relative bargaining power, a recurrent question in the theory of bargaining. We find that both entrepreneurs and workers have high discount factors, and no evidence that entrepreneurs have bigger bargaining power, as usually assumed.
\end{abstract}

Keywords: Delays; sequential bargaining; structural estimation.

JEL Nos.: J50, C73, C78.

(C) by the authors. All rights reserved. Short sections of text, not to exceed two paragraphs, may be quoted without explicit permission provided that full credit, including (C) notice, is given to the source. 


\section{Introduction}

The negotiation between workers and entrepreneurs is a major bargaining game in economics. In many cases, agreements are delayed as the parties continue negotiations, or agreements are never reached. While standard, complete information bargaining models usually predict immediate agreement, the private information environment is the usual explanation for observing delays in games with a stationary structure. Players delay agreements to credibly reveal preferences which result in a more favorable outcome of the game. Kennan and Wilson (1993) provide an excellent survey of this literature.

But the private information framework is not always easy to justify. In many circumstances, even at the firm level, the collective negotiation between the representatives of the firm and the trade union takes place under basically the same set of information at both sides of the negotiation table. Specially in large firms, the assumption of complete information seems a sensible one. In most of these large companies, unions are represented in the board of directors. In addition, large firms must be audited by law, specially if they quote in the stock market, and that information is public and widely available. Moreover, trade unions have the means to extensively collect information in and outside the firm.

Under complete information, uniqueness generally implies immediate agreement. That is why traditional bargaining models allow for delays only if there are multiple subgame perfect equilibria with nonstationary strategies (see, e.g. Fernandez and Glazer (1991) and Haller and Holden (1990), or Sakovics (1993) 
under simultaneous moves). This makes these models unsuitable for empirical analysis. Therefore, to study the situation we have just pointed out, we need a different framework where, in spite of the existence of complete information and delays, equilibrium is unique so we can still empirically analyze the predictions of our model.

Merlo and Wilson (1995) offer a different approach: delays in bargaining are the result of the uncertainty about the size of the cake and the identity of the proposer. In their model, under some circumstances, there is a unique stationary subgame perfect equilibrium. One of the advantages of this model is that it can be estimated. In fact, Merlo (1997) structurally estimates a stochastic bargaining model of government formation in postwar Italy.

Here, following Merlo and Wilson (1995), we build a model that help us to study the collective bargaining in large Spanish firms. However, in sharp contrast with the approach of Merlo (1997), in which the game has transferable utility, we assume that the discount factors of the players are different and, therefore, utility is not transferable. This feature captures an important issue in the labor market negotiation, the relative bargaining power of the players. It is generally assumed that workers are less patient than entrepreneurs giving the firms more negotiation power; but the estimation of our model may or may not confirm this intuition.

We use data from the "Negociación Colectiva en las Grandes Empresas" (Collective Bargaining in Large Firms Survey), a yearly Spanish survey on bargaining issues. The NCGE provides data on bargaining offers, timing of the negotiation, strike activity, wage changes and other variables, for Spanish firms with more than 
200 employees.

The nature of the negotiation of these large firms provides a very good benchmark case to test this approach to the labor market negotiation. At the firm-level, the unions, represented by their elected work councils, always start the negotiation process by making a wage increase claim. The institutional setting is such that the firm must counteroffer immediately. This process is also followed in the negotiations at the sector-level and in the economy-wide agreements.

The literature on empirical collective bargaining is very large. One of the basic pillars in which this literature is founded is the existence of incomplete information among the agents. An important part of this literature is concerned with the effects of strikes and strike duration over collective bargaining. Card (1990) provides an excellent survey of the microeconometric literature on these issues. Crampton et al. (1999), Crampton (1994) and Ondrich and Schnell (1993) are some of the uncountable many recent contributions in that area. Two other important aspects of this literature are the analysis of the effects of holdouts (the continuation of negotiations beyond the contract expiry date) in wage bargaining (see Crampton and Tracy, 1992; Gu and Kuhn, 1998 and van Ours and van de Wijngaert, 1996); and the analysis of the effect of unions on the structure of wages (see Card, 1996).

Although the literature on collective bargaining is large, our approach is somehow different to that followed by most of it. Very few models have been tested with data and have been estimated solving the actual game between the players. Most of the studies ignore the negotiation process and stress the analysis of the 
outcomes. The most important reason why they do that is the lack of data on the succession of offers and counteroffers that each of the agents make. However the use of a structural approach allows us to concentrate in the negotiation process using the restrictions provided by the bargaining model. In this sense, estimates of structural parameters are a valuable information we could not get from the reduced form analysis. This information allows us to evaluate the effects of changes in the bargaining procedure or measure the advantage from proposing, something that it is not possible with the standard reduced form approaches.

The rest of the paper is organized as follows. In sections 2 and 3 we describe the rules under which the negotiation takes place and the bargaining model. Section 4 describes the data set. Section 5 explains the econometric specification. The results of the empirical analysis are presented in Section 6. Finally, conclusions are included in Section 7.

\section{Collective Bargaining in Spain}

There are two different types of regulations that affect the process of collective bargaining in Spain. On the one hand, there is a legal framework that regulates how collective bargaining has to be conducted (see subsection 2.1). On the other, there are several legal provisions that constrain the outcome of collective bargaining (see subsection 2.2). 


\subsection{The Rules of the Game}

In Spain, collective bargaining is a worker's right recognized by the Worker's Statute (Ley del Estatuto de los Trabajadores, LET) ${ }^{1}$ since 1980. In order to exercise this right, workers have to elect their representatives every four years at the firm level. All workers, and not only those belonging to unions, can be elected; even though in practice, more than $70 \%$ of all the elected representatives belong to either one of the two major trade union confederations: the socialist, Unión General de Trabajadores (UGT), and the communist, Comisiones Obreras (CCOO). These worker representatives are the ones who, then, negotiate with the employers. All agreements that are the result of collective bargaining are enforceable, and apply to all workers whether or not they belong to a union.

The structure of collective bargaining is decided by the worker representatives (unions and workers' associations), and employers. In practice, collective bargaining takes place at three different levels: economy-wide, industry level, and firm-level. Economy-wide agreements do not take place every year. The agreements reached at the industry-level are supposed to be enforceable for all workers and employers in that industry. In practice, the effectiveness of the agreements reached at the industry level is not very clear. The reason is that many workers that do not belong to any union are employed in small firms. Since they have very little information (if any) about the agreements reached at the industry level, they cannot make employers comply with them. In any case, around $75 \%$ of the

\footnotetext{
${ }^{1}$ Of all laws regulating the labor market, the LET is the most important. It was reformed in 1984,1994 and 1997.
} 
wage-earners in the private sector are covered by collective bargaining agreements. Of all those, only $15 \%$ are covered by agreements reached at the firm-level.

At the firm-level, the structure of collective bargaining is as follows. There are two main players in the negotiation: workers and employers. Always the unions and/or the workers' associations, represented by their elected work councils, make a wage increase claim. The institutional setting is such that the firm must counteroffer immediately (see Jimenez-Martín, 1999).

The rules established to eliminate all conflicts between collective bargaining agreements can be established by employers' associations, and workers' associations and unions. It is implicitly assumed that the agreements that are in operation cannot be modified by a new agreement. But, in practice, there are few conflicts because economy-wide agreements are only enforceable for the signing parties and agreements at the industry-level are considered as the minimum standard accepted for the negotiation at the firm-level.

Under some circumstances, the Government can extend the agreements to a firm or an industrial sector in which there is no collective bargaining agreement in operation, or there is no higher-level agreement which apply. Usually the Government would extend the agreement of a firm or industrial sector to another firm or sector that enjoys similar economic circumstances. The extension could be realized if requested by the employers or the workers' representatives of the affected workers. 


\subsection{Legal Provisions Constraining the Outcome of Collective Bargain- ing}

There are basically two legal provisions that constraint the outcome of collective bargaining: minimum wage laws and working hours regulations. The current minimum wage policy was introduced in 1963. The policy consists of a statutory minimum fixed annually by the Government. Before fixing this minimum, the Government consults with employers' and workers' associations. The law calls for a review of the statutory minimum wage every six months and when Government's forecast inflation is substantially different to actual inflation. According to the LET, the Government must take into account the following when fixing the minimum wage: cost-of-living index, productivity changes, the share of workers' compensation in national income, and the current economic situation. In practice, inflation is the most important determining factor. This minimum is binding across the economy without distinction by occupation, work status or contractual relationship with the employer; even though there is a difference between workers aged under 18 and those aged over 18 .

Working hours are usually fixed by collective bargaining agreements at the industry and the firm levels. The maximum number of normal working hours per week is set, by law, at 40 hours. In addition, the remuneration of the hours worked overtime is also included in collective bargaining agreements. Other than that, there is a lot of flexibility in the organization of these working hours, and it is usually included in the agreements as well. 


\section{The Model}

We propose a bargaining model where the size of the surplus to be divided follows a stochastic process. The situation we analyze here is the collective negotiation between trade unions and employer organizations. The object of bargaining is the allocation of the cake, i.e. the allocation of firms' surplus between workers and entrepreneurs.

Therefore, in our game we only consider two players: trade unions and employer associations. Although the model can obviously be extended to any finite number of players, the Spanish collective negotiation is such that there is only one employer association and two main unions that, while negotiating at the firm level, usually act collectively. This is the reason why we assume that workers and entrepreneurs are the only players in the game. In what follows, we will denote by subscript $e$ the employer association or the entrepreneurs and by subscript $w$ the trade unions or the workers. Let $S \subset R_{+}$be a compact set of possible states of the world, where a state $s \in S$ represents the surplus to be allocated, and let $\sigma$ denote a temporally homogeneous Markov process with state space $S$ and transition probability distribution function $P(\cdot \mid s)$. We will refer to the surplus $s \in S$ that is realized in period $t=0,1, \ldots T$, as a state $(s, t)$.

The institutional structure of the bargaining procedure we consider here is as follows. Upon the realization of a state $(s, t)$, the trade unions (workers) make a proposal, i.e. a split of the surplus consistent on a wage increase and some other benefits for workers, to which the employer association (entrepreneurs) responds 
accepting or rejecting it. If the entrepreneurs reject the offer, then they become the proposers and make a new offer. This process continuous until an agreement is reached. ${ }^{2}$

An outcome of this bargaining game is $(\tau, \chi)$, where $\tau$ denotes the periods in which a proposal is accepted, and $\chi$ is a feasible allocation of the surplus. Every outcome implies a payoff $\beta_{e}^{\tau} \chi_{e}$ for the entrepreneurs and $\beta_{w}^{\tau} \chi_{w}$ for the workers, where $\beta_{e}$ and $\beta_{w}$ are the discount factors for entrepreneurs and workers respectively, and $\chi_{e}$ and $\chi_{w}$ are the feasible allocation of surplus for entrepreneurs and workers, respectively.

Given that all negotiations in our data set end in a finite time, our game is finite as well. This implies that there is a unique subgame perfect payoff that it is stationary. However, since the utility is linear and the outcome of the cake is in $R_{+}$, there also exists a unique subgame perfect stationary payoff for the infinite game. $^{3}$

In Merlo (1997) the set of states in which the players agree depends only on the unique discount factor, the cake function and the Markov process, and it is independent of the proposer in each state. In addition, the gains to a player from being the proposer in a state in which agreement occurs are independent of who the proposer is. This is what Merlo and Wilson (1998) call the separation principle for stationary subgame perfect equilibria of generic multilateral stochastic bargaining

\footnotetext{
${ }^{2}$ Labor market negotiations often end without agreement. This is not the case in our data set. For some examples in which negotiations can break down without agreement, see Diaz-Moreno and Galdón-Sánchez (2000a and 2000b).

${ }^{3}$ Clearly, for any discount factor $\delta \geq \max \left\{\beta_{e}, \beta_{w}\right\}$, Condition (C') in Merlo and Wilson (1995) is satisfied.
} 
games.

The separation principle does not apply when players have different discount factors. Analyzing empirically the bargaining process in this case implies considering explicitly the successions of offers and counteroffers that each of the agents make. This is a more "natural" environment for the bargaining situations that take place in the labor market. However, there are some costs of assuming this specification: the need to know who is the proposer in every stage of the negotiation and the lost of the stopping time property of the game implied by the separation principle.

To characterize the subgame perfect equilibrium, we use the fact that at any stage in which agreement occurs, the proposer can extract from the other player any surplus in excess of its expected payoff from the delaying agreement until next period. The subgame perfect payoffs for the players are the unique solution to the following system of equations:

$$
\begin{gathered}
v_{i}(s, t, i)=\max \left\{s-v_{j}(s, t, i), \beta_{i} \int v_{i}\left(s^{\prime}, t+1, j\right) d P\left(s^{\prime} \mid s\right)\right\} \\
v_{j}(s, t, i)=\beta_{j} \int v_{j}\left(s^{\prime}, t+1, j\right) d P\left(s^{\prime} \mid s\right) \\
t=1 \ldots T, v_{j}(s, T+1, i)=0, \quad i, j=\left\{\begin{array}{l}
i=w \text { and } j=e \text { if } t \text { odd } \\
i=e \text { and } j=w \text { if } t \text { even }
\end{array}\right.
\end{gathered}
$$

where $s^{\prime}$ denotes the next period surplus and $T$ is the last period of the negotiation. Here, $v_{i}(s, t, i)$ is the payoff to player $i$ when player $i$ is the proposer and the state 
is $(s, t)$, and $v_{j}(s, t, i)$ is the payoff to player $j$ in state $(s, t)$ when player $i$ is the proposer. To reach an agreement, the proposer has to offer to the other party its continuation value. The proposer does so if what it is left, $s-v_{j}(s, t, i)$, is bigger than its own continuation value.

\section{The Data}

The data we use are from the "Negociación Colectiva en las Grandes Empresas" (hereafter NCGE), a yearly Spanish survey on bargaining issues. The NCGE provides data on bargaining offers, timing of the negotiation, strike activity, wage changes and other variables, for all those Spanish firms with more than $200 \mathrm{em}-$ ployees in 1978, year in which the survey started.

Despite the fact that the survey runs from 1978, we have only had access to the results of the 1988 survey. Therefore, the results we report here have been obtained using this year, which contains data on collective negotiations for firms belonging to 9 different economic sectors. ${ }^{4}$ For the purpose of our exercise, this year proves to be enough. The results should be consistent if we had used all the years available since the negotiation process has not changed much.

We constructed our sample by selecting from the raw data only those firms that reported information about the duration of their negotiations. This means that we have excluded from our analysis those firms that did not report information about

\footnotetext{
${ }^{4}$ There are 10 economic sectors in the original data set, but only 2 firms were surveyed in the agricultural sector. This is the reason why we have only consider the 9 nonagricultural sectors. In any case, the impact of these two data on the estimation results for the discount factors is negligible.
} 
the date in which their negotiation starts, the date in which their negotiation ends or both. Moreover, we eliminated from the sample those units for which the date of conclusion of the negotiations appears as being previous to the date in which the negotiation started. We also eliminated those firms that did not report their number of workers. Table 1 reports some statistics regarding the size of the firms and the duration of the negotiations for the 1988 survey.

The data are disaggregated in nine economic sectors (1 to 9$).^{5}$ The total number of firms in our data set is 484 (545 negotiation units or negotiations). ${ }^{6}$ The total number of workers in these firms is 672,226 . Regarding the size of the firms, their average size is $1,388.9$ workers. The biggest firm in our sample has 52,889 workers, and the smallest 100 workers. $^{7}$ Regarding the duration of the negotiations, the average duration per negotiation unit is 104.2 days, being the longest of these negotiations 1,226 days and the shortest 1 day.

To study how representative of the Spanish economy our sample is, we also compare our database with the 1988 data for the whole Spanish economy. The results of this comparison are available in Table 2 . This table contains the indus-

\footnotetext{
${ }^{5}$ Description of sectors: $1=$ Energy and water distribution, $2=$ Mining and chemicals, $3=$ Metal industries, $4=$ Non-durable manufacturing, $5=$ Construction, $6=$ Trade, $7=$ Transport and communications, $8=$ Finance, banking and services to firms, $9=$ Social and personal services.

${ }^{6}$ The original data set contained 718 firms (815 negotiation units or negotiations). For some firms, there are more than one bar gaining unit. Since most of the time the negotiation duration is different for the different negotiation units of the same firm, we kept as much bargaining units as possible for our analysis. The number of negotiation units coincide, therefore, with the total number of negotiations.

${ }^{7}$ Even though our survey includes all firms with more than 200 workers, it also follows firms through time. Therefore, if a firm reduces its number of workers from one year to the next, this does not necessarily mean that the firm is excluded from the survey.
} 
trial distribution of collective negotiation at the firm level in 1988 for the NCGE and the total economy. The data for the whole economy are from the "Boletin de Estadísticas Laborales" (Labor Statistics Bulletin, BEL), a publication that contains, among others, those Spanish labor statistics related to collective negotiation.

As it can be seen, the 545 negotiations in our database represent around $20 \%$ of the total firm-level negotiations of the economy (2,790 negotiations). The number of workers affected in our database, 672,226 , represents around the $63 \%$ of the total number of workers affected by firm-level agreements $(1,066,188$ workers).

\section{Econometric Specification}

The predictions of our bargaining model depend on the discount factors of the two players $\left(\beta_{e}, \beta_{w}\right)$, the distribution function $P_{i}$ describing the surplus process for every sector, and the terminal date of the negotiation, $T$. Therefore, we assume that workers and entrepreneurs irrespective of their sector have the same discount factor, i.e. the discount factor for each player is identical across sectors; ${ }^{8}$ but the process for the surplus is group specific allowing for a different technology in each sector. These are the structural components of our model.

Since we do not observe the surplus levels, we assume that they are generated by a distribution function $P_{i}$ over the set, $S=[0, c], \bar{c}<\infty$, of possible outcomes. Therefore we make $S$ identical for each group. We also assume a specific paramet-

\footnotetext{
${ }^{8}$ It does not seem sensible to assume that the rate of time preference depends on the sector in which people work.
} 
ric functional form for $P_{i}(\cdot \mid s)=P_{i}(\cdot)$ (i.e., the sequence of surplus levels for each sector is generated by i.i.d. draws from a common distribution $P_{i}$ ) and derive maximum likelihood estimates of the structural parameters of the model.

Since $T_{\max }$ is a strongly consistent estimator of $T$ and converges to $T$ at a faster rate $(N)$ than the maximum likelihood estimators of the other parameters $(\sqrt{N})$, we use $T^{*}=T_{\max }$ and estimate the rest of the parameters conditional on such an estimate. ${ }^{9}$ Under this assumption, given that $T^{*}$ is even, the sequences of surplus levels that induce agreement for the proposer in sector $i, i=1 \ldots . .9$, $\left(s_{i n}^{*}\right)_{n=1}^{T^{*}}$, and for the other player, $\left(d_{i n}^{*}\right)_{n=1}^{T^{*}}$, are the following:

$$
\begin{gathered}
s_{i T}^{*}=0 ; d_{i T}^{*}=0 \\
s_{i T-1}^{*}=\beta_{w} E\left(s_{i}\right) ; d_{i T-1}^{*}=0 \\
d_{i n}^{*}=\left\{\begin{array}{l}
\beta_{e} s_{i n+1}^{*} \text { if } n \text { is even } n=T-2, \ldots .1 \\
\beta_{w} s_{i n+1}^{*} \text { if } n \text { is odd }
\end{array}\right. \\
s_{i n}^{*}=\left\{\begin{array}{c}
\beta_{w}\left[\int_{s_{i n+1}^{*}}^{\bar{c}}+d_{i n+1}^{*}\left(s_{i}-s_{i n+1}^{*}\right) d s_{i}+\beta_{w} s_{i n+2} \int_{0}^{s_{i n+1}^{*}+d_{i n+1}^{*}} d s_{i}\right] \text { if } n \text { is even } \\
\beta_{e}\left[\int_{s_{i n+1}^{*}}^{\bar{c}}+d_{n+1}^{*}\right. \\
\left.\left(s_{i}-s_{i n+1}^{*}\right) d s_{i}+\beta_{e} s_{i n+2} \int_{0}^{s_{i n+1}^{*}+d_{i n+1}^{*}} d s_{i}\right] \text { if } n \text { is odd }
\end{array}\right.
\end{gathered}
$$

$n=T-2, \ldots .1$, where $n$ is the negotiation period, $s_{i n}^{*}$ is the surplus level for the proposing player that induce agreement in the negotiation period $n$ in group $i, d_{i n}^{*}$ is the surplus level for the other player that induce agreement in the negotiation

\footnotetext{
${ }^{9}$ This is the same result used by Merlo (1997) and Flinn and Heckman (1982).
} 
period $n$ in sector $i$, and $\bar{c}$ is the maximum value in the support of the distribution of $P_{i}$.

Given the sequences of surplus levels that induce agreement in each group, we can construct the likelihood function. Let $\Gamma(i, n, w)$ be an indicator function that takes value 1 if an agreement in $n$ is reached when the trade union is the proposer ( $n$ is odd) for a negotiation in a firm of sector $i$. And it takes value 0 if there is a delay in $n$ when the proposer is $w$ ( $n$ is odd) and the negotiation is in a firm of sector $i$. Then, the probability that the players will agree in state $(s, n)$ given that they have not agreed up to $n$, the proposer is $w$, and the group is $i$, is:

$$
\begin{gathered}
\operatorname{Pr}(\Gamma(i, n, w)=1 / \text { delay to } n, s)= \\
\operatorname{Pr}\left(s \geq \int\left(\beta_{w} v_{w}\left(s^{\prime}, n+1, e\right)+\beta_{e} v_{e}\left(s^{\prime}, n+1, e\right)\right) d P_{i}\right)
\end{gathered}
$$

Similarly, the probability that the player will delay agreement in state $(s, n)$ given that they have not agreed up to $n$, the proposer is $w$, and the group is $i$, is:

$$
\begin{gathered}
\operatorname{Pr}(\Gamma(i, n, w)=0 / \text { delay to } n, s)= \\
\operatorname{Pr}\left(s<\int\left(\beta_{w} v_{w}\left(s^{\prime}, n+1, e\right)+\beta_{e} v_{e}\left(s^{\prime}, n+1, e\right)\right) d P_{i}\right)
\end{gathered}
$$

Note that the case in which the entrepreneur is the proposer is exactly symmetrical to the case just described.

Given the small number of observations we have, we assume a simple form for $P_{i}$ that depends only in two parameters, $\alpha_{i}$ and $\bar{c}$. The specific form we choose is 
$P\left(s ; \alpha_{i}, \bar{c}\right)=\left(\frac{s}{\bar{c}}\right)^{\alpha_{i}}, \alpha_{i}>0$. Therefore, the probability of observing a negotiation process for $n-1$ periods in sector $i$ followed by an agreement when the proposer is $k$ is:

$$
\operatorname{Pr}(\Gamma(i, n, k)=1 / \text { delay to } n, s)=\Pi_{t=1}^{n-1}\left(\frac{s_{i t}^{*}+d_{i t}^{*}}{\bar{c}}\right)^{\alpha_{i}}\left[1-\left(\frac{s_{i n}^{*}+d_{i n}^{*}}{\bar{c}}\right)^{\alpha_{i}}\right]
$$

and, similarly, the probability of observing a negotiation process for $n-1$ periods followed by no agreement becomes:

$$
\operatorname{Pr}(\Gamma(i, n, k)=0 / \text { delay to } n, s)=\Pi_{t=1}^{n-1}\left(\frac{s_{i t}^{*}+d_{i t}^{*}}{\bar{c}}\right)^{\alpha_{i}}
$$

The $(\log )$ likelihood function is obtained by summing the logs of the right hand side of (5.4) and (5.5) over all the elements of the sample. The parameters to estimate are $\beta_{w}, \beta_{e}$ and $\alpha_{i}, i=1 \ldots .9$. Even though $\bar{c}$ appears in equations (5.4) and (5.5), it is just a scale factor and it does not appear in the likelihood function.

\section{Results}

The estimated parameters of our model are reported in Table 3 . The first thing to be noticed is the value of the discount factors. The value for $\beta_{e}$ is .96223 and for $\beta_{w}$ is .95647. These high values are not surprising given that the time period in our model is a week. An important question, as we have already pointed out, is the existence of differences in the value of the discount factors, since this differences affect the relative bargaining power of the agent and also the computational 
burden of the model's solution. As it can be seen at a glance, both values are very close. We tested the hypothesis of $\beta_{e}=\beta_{w}$ and were unable to reject it. ${ }^{10}$

The next step is the analysis of the sector specific parameters, $\alpha_{i}$. They take different values that range from the highest of .11670 for $\alpha_{2}$ (mining and chemical), to the lowest of .02393 for $\alpha_{8}$ (finance, banking and services to firms). There are five $\alpha^{\prime} s$ with values bigger to .1, and they are those corresponding to sectors 2 (mining and chemicals), 3 (metal industries), 4 (non-durable manufacturing) 6 (trade) and 9 (social and personal services). The remaining four sectors range between the aforementioned lowest value of sector 8 and the value of .07528 obtained by sector 7 (transport and communications).

If we compare the values of $\alpha_{i}$ in Table 3 with those of the average negotiation duration in Table 1, we observe a clear inverse relation between both. The longer the average negotiation duration, the smaller the value of $\alpha_{i}$. This is not surprising since a low $\alpha_{i}$ implies a distribution of surplus levels skewed toward zero, and therefore the probability distribution puts more mass in low levels of surplus. In this way, longer negotiations are needed in order to get a level of surplus high enough to induce an agreement.

It seems that in those sectors in which the benefits increased on average more than $50 \%$ in 1987 , i.e. the year before our negotiations took place, the duration of the negotiation was shorter (see Ministerio de Economía y Hacienda, 1989). This is the case for mining and chemicals ( $80.7 \%$ increase), non-durable manufacturing ( $57.8 \%$ increase), personal services ( $126.5 \%$ increase) and trade ( $50 \%$ increase). ${ }^{10}\left(-2\left(\ln \left|L_{R}\right|-\ln \left|L_{U}\right|\right)=.0005\right)$. 
Even though this is not the only reason why some negotiations are shorter than others, it can be an indicator for high values of $\alpha_{i}$, or a high probability of getting a high level of surplus in shorter negotiations.

Table 4 reports evidence on the fit of the model to the data. It compares the density function of the negotiation duration predicted for the model aggregating by sectors, weighting every sector by its relative frequency, to the joint empirical density. ${ }^{11}$ We use this procedure since, of course, the model does not give any information on the number of firms in each sector. In this table we report some of the 176 data of the empirical marginal density and the density we have constructed since we think this is enough to appreciate the good fit of the model. The $\chi^{2}$ test confirms this fact. ${ }^{12}$ As it can be seen in Table 4 , the $\chi^{2}$ test does not reject the model for any significance level. Figure 1 confirms the performance of the model when compared to the observed duration data.

It is also interesting to compare the performance of the model by economic sectors. Figures 2 to 10 show the performance of the model when compared to

${ }^{11}$ The density function of the negotiation duration predicted by the model is:

$$
f(\tau)=\sum_{i=1}^{9} \frac{n_{i}}{N}\left[\Pi_{t=1}^{\tau-1}\left(\frac{s_{i t}+d_{i t}}{\bar{c}}\right)^{\alpha_{i}}\left[1-\left(\frac{s_{i \tau}+d_{i \tau}}{\bar{c}}\right)^{\alpha_{i}}\right]\right]
$$

Where $n_{i}$ is the number of negotiations in sector $i$ and $N$ is the total number of negotiations.

${ }^{12}$ The goodness-of-fit $\chi^{2}$ statistic is defined as:

$$
N \sum_{\tau=1}^{T} \frac{\left[f(\tau)-f^{\circ}(\tau)\right]^{2}}{f^{\circ}(\tau)} \sim \chi^{2}(T-1)
$$

where $f$ is the empirical density function of negotiation times and $f^{\circ}$ is the maximum likelihood estimate. $N$ is the total number of observations and $T=176$. The degrees of freedom are an upper bound since we do not take into account that the parameters in the model are estimated. 
the observed duration data for each sector. Despite the fact that by our econometric specification the marginal densities predicted by the model have the same support than the marginal of sector 8 , where the longest negotiation took place, the adjustment is quite good. One exception is sector 9 (see Figure 10), but the number of negotiations that our data set reports for this sector is very low. Allowing in the estimation for sector specific terminal dates for the negotiation would greatly increase the adjustment of the marginal density of each sector, but at the theoretical cost of assuming that the bargaining games played at each sector are different.

It would be interesting to compare our structural estimates to other labor market negotiation analysis of this sort, but we have not found any comparable studies. In a previous paper (see Díaz-Moreno and Galdón-Sánchez, 2000a), we found a higher value for $\beta$ (1.0930). The bargaining model in this case had only one discount factor and was estimated using a much shorter data base on collective negotiation of economy-wide agreements in Spain. A much lower value (.642) is found in Merlo (1997) for a similar model but using data of negotiation for government formation in Italy.

Our estimated values of $\beta$ are closer to the values usually found in the dynamic macroeconomic literature. This is consistent with the fact that Merlo's agents are Italian politicians and our agents are workers and entrepreneurs, the same type of agents that are found in the macroeconomic literature. In spite of this, if we compare our values with those used in the Real Business Cycles (RBC) literature (i.e. a quarterly value of .9870 quarterly, which implies a weekly value of .9990 , 
see Cooley and Prescott, 1995) they are still lower.

\section{Conclusions}

The existence of delays is one of the most important features of collective bargaining. In contrast with the traditional view based on private information, we have shown that a bargaining model with complete information and a stochastic process for the surplus to be divided among the players, very much on the spirit of the productivity shock that generates business cycles in the RBC literature, can explain at least part of this issue.

In this way, the duration data show a very good correspondence with the predictions of the model regardless of the limitations imposed by the parametric specification adopted. In addition, the parameter values are in the line of those found in the dynamic macroeconomic literature.

An important question addressed by of our model is the relative bargaining power of workers and entrepreneurs. Analyzing empirically the bargaining process in the case we study implies considering explicitly the successions of offers and counteroffers that each of the agents makes. But this allows us to estimate different discount factors for every player which is a measure of their bargaining power. The estimated values of the discount factors of workers and entrepreneurs are very similar. Therefore, the traditional view that entrepreneurs have more bargaining power because they control the resources while the workers depend on their wages does not seem to work in this environment.

The theoretical formulation contains some simplifying assumptions, and the 
sensitivity of the results to those assumptions is an important issue yet to be addressed. In this sense, our results have to be taken carefully; but in our view, no less than those not based in a structural approach. We think the paper is an important step in bringing sequential bargaining models to the data and show the usefulness of structural estimation as a tool to understand the full set of implications of general bargaining models.

\section{References}

[1] Card, D. (1990), Strikes and Bargaining: A Survey of the Recent Empirical Literature, American Economic Review (AEA Papers and Proceedings), 80, 410-15.

[2] Card, D. (1996), The Effect of Unions on the Structure of Wages: A Longitudinal Analysis, Econometrica, 64(4), 957-79.

[3] Cooley, T. and E. Prescott (1995), Economic Growth and Business Cycles, in Frontiers of Business Cycle Research, T. Cooley ed., Princeton University Press.

[4] Crampton, P.C., M. Gunderson and J.S. Tracy (1999), The Effect of Collective Bargaining Legislation on Strikes and Wages, Review of Economics and Statistics, 81 (3), 475-87.

[5] Crampton, P.C. and J.S. Tracy (1992), Strikes and Holdouts in Wage Bargaining: Theory and Data, American Economic Review, 82, 100-21.

[6] Crampton, P.C. and J.S. Tracy (1994), Wage Bargaining with Time-Varying Threats, Journal of Labor Economics, 12, 594-617.

[7] Díaz-Moreno, C. and J.E. Galdón-Sánchez (2000a), Collective Bargaining under Perfect Information. The Negotiation of Economy-Wide Agreements, London School of Economics manuscript. 
[8] Díaz-Moreno, C. and J.E. Galdón-Sánchez (2000b), An Estimable Stochastic Model of Sequential Bargaining with Complete Information and Nontransferable Utility, London School of Economics manuscript.

[9] Eckstein, Z. and K.I. Wolpin (1995), Duration to First Job and the Return to Schooling: Estimates from a Search-Matching Model, Review of Economic Studies, 62, 263-86.

[10] Flinn, C. and J.J. Heckman (1982), New Methods for Analyzing Structural Models of Labor Force Dynamics, Journal of Econometrics, 18, 115-68.

[11] Fernandez, R. and J. Glazer (1991), Striking for a Bargain between Two Completely Informed Agents, American Economic Review, 81, 240-52.

[12] Gu, W. and P. Kuhn (1998), A Theory of Holdouts in Wage Bargaining, American Economic Review, 88, 428-49.

[13] Haller, H. and S. Holden (1990), A Letter to the Editor on Wage Bargaining, Journal of Economic Theory, 60, 232-36.

[14] Jimenez-Martín, S. (1999), Controlling for Endogeneity of Strike Variables in the Estimation of Wage Settlement Equations, Journal of Labor Economics, $17(3), 583-606$.

[15] Jimeno, J.F. and L. Toharia (1994), Unemployment and Labour Market Flexibility: Spain, International Labour Office, Geneva.

[16] Kennan, J. and R.B. Wilson (1993), Bargaining with Private Information, Journal of Economic Literature, 31, 45-104.

[17] Kennan, J. and R.B. Wilson (1989), Strategic Bargaining Models and Interpretation of Strike Data, Journal of Applied Econometrics, 4 (suppl; Dec.), S87-S130.

[18] Merlo, A. (1997), Bargaining Over Governments in a Stochastic Environment, Journal of Political Economy, vol. 105, No. 1, 101-31.

[19] Merlo, A. and C. Wilson (1998), Efficient Delays in a Stochastic Model of Bargaining, manuscript, Economic Theory, 11, 39-55. 
[20] Merlo, A. and C. Wilson (1995), A Stochastic Model of Sequential Bargaining with Complete Information, Econometrica, vol. 63, No. 2, 371-99.

[21] Ministerio de Economía y Hacienda (1989), La Negociación Colectiva en las Grandes Empresas en 1988. Principales características económicas, Dirección General de Política Económica, Ministerio de Economía y Hacienda, Madrid.

[22] Ondrich, J.I. and J.F. Schnell (1993), Strike duration and the Degree of Disagreement, Industrial relations, 32 (3), 412-31.

[23] Osborne, M.J. and A. Rubinstein (1990), Bargaining and Markets. San Diego: Academic Press.

[24] Sakovics, J. (1993), Delay in Bargaining Games with Complete Information, Journal of Economic Theory, 59, 78-95.

[25] van Ours, J.C. and R.F. van de Wijngaert (1996), Holdouts and Wage Negotiations in the Netherlands, Economics Letters, 53, 83-88.

[26] Wolpin, K.I. (1987), Estimating a Structural Search Model: The Transition from School to Work, Econometrica, 55, 801-17. 
Table 1. Some NCGE Statistics, 1988

\begin{tabular}{c|c|cccc|ccc}
\hline \multirow{2}{*}{ Sector } & Number of & \multicolumn{5}{|c|}{ Number of Workers } & \multicolumn{3}{c}{ Negotiation Duration $\left(\right.$ days) $^{2}$} \\
\cline { 3 - 8 } & Firms & Total & Average & Maximum & Minimum & Average & Maximum & Minimum \\
\hline 1 & 29 & 83,368 & $2,874.7$ & 19,650 & 240 & 108.6 & 459 & 1 \\
2 & 81 & 50,976 & 629.3 & 3,122 & 124 & 76.7 & 455 & 1 \\
3 & 102 & 162,693 & $1,595.0$ & 19,509 & 136 & 85.6 & 391 & 1 \\
4 & 107 & 73,751 & 689.3 & 11,955 & 100 & 78.2 & 315 & 1 \\
5 & 12 & 12,876 & $1,073.0$ & 5,100 & 136 & 120.8 & 240 & 21 \\
6 & 26 & 59,039 & $2,270.7$ & 32,100 & 113 & 82.5 & 473 & 1 \\
7 & 30 & 101,025 & $3,367.5$ & 52,889 & 102 & 98.9 & 279 & 11 \\
8 & 89 & 112,685 & $1,266.1$ & 15,900 & 209 & 197.7 & 1,226 & 1 \\
9 & 8 & 15,813 & $1,976.6$ & 12,572 & 182 & 79.9 & 139 & 14 \\
\hline
\end{tabular}


Table 2. Industrial Distribution of Collective Negotiation in 1988

\begin{tabular}{|c|c|c|c|c|}
\hline \multirow[b]{3}{*}{ Sector } & \multicolumn{2}{|c|}{ NCGE } & \multicolumn{2}{|c|}{ Total Economy } \\
\hline & Number of & Workers & Number of & Workers \\
\hline & Negotiations & Affected & Negotiations & Affected \\
\hline 1 & 35 & 83,368 & 155 & 80,219 \\
\hline 2 & 90 & 50,976 & 306 & 94,774 \\
\hline 3 & 119 & 162,693 & 422 & 256,755 \\
\hline 4 & 125 & 73,751 & 504 & 105,751 \\
\hline 5 & 12 & 12,876 & 25 & 9,326 \\
\hline 6 & 31 & 59,039 & 369 & 47,051 \\
\hline 7 & 32 & 101,025 & 255 & 202,535 \\
\hline 8 & 93 & 112,685 & 99 & 28,545 \\
\hline 9 & 8 & 15,813 & 655 & 241,232 \\
\hline Total & 545 & 672,226 & 2,790 & $1,066,188$ \\
\hline
\end{tabular}

Source: NCGE 1988 and Boletin de Estadisticas Laborales (Ag./Sep. 1992). 
Table 3. Structural estimates

(asymptotic standard errors in parentheses)

\begin{tabular}{lll}
$\beta_{e}$ & .96223 & $(.00010)$ \\
$\beta_{w}$ & .95647 & $(.00010)$ \\
$\alpha_{1}$ & .06603 & $(.00053)$ \\
$\alpha_{2}$ & .11670 & $(.00056)$ \\
$\alpha_{3}$ & .10454 & $(.00045)$ \\
$\alpha_{4}$ & .11366 & $(.00046)$ \\
$\alpha_{5}$ & .05522 & $(.00190)$ \\
$\alpha_{6}$ & .10509 & $(.00087)$ \\
$\alpha_{7}$ & .07528 & $(.00133)$ \\
$\alpha_{8}$ & .02393 & $(.00001)$ \\
$\alpha_{9}$ & .11518 & $(.02492)$ \\
\hline
\end{tabular}

Log-Likelihood $\quad-1956.049$ 
Table 4. Density of Negotiation Duration

\begin{tabular}{lcc}
\hline Week & Data & Model \\
\hline 1 & .07463 & .07069 \\
2 & .03172 & .06535 \\
3 & .03731 & .06044 \\
4 & .04478 & .05590 \\
5 & .05224 & .05173 \\
6 & .03172 & .04787 \\
7 & .03358 & .04432 \\
8 & .05037 & .04104 \\
9 & .02239 & .03801 \\
10 & .08396 & .03522 \\
20 & .02985 & .01672 \\
30 & .00560 & .00825 \\
40 & .00000 & .00427 \\
50 & .00000 & .00233 \\
60 & .00000 & .00134 \\
70 & .00000 & .00081 \\
80 & .00000 & .00051 \\
90 & .00000 & .00033 \\
100 & .00000 & .00022 \\
150 & .00000 & .00004 \\
176 & .00187 & .00028 \\
\hline Goodness of Fit & & \\
$\chi^{2}$ test & & $1,170.839$ \\
$\chi_{175}^{2} 1,170.839$ & & 0.000 \\
\hline & & \\
\hline & &
\end{tabular}


Figure 1: Density Functions

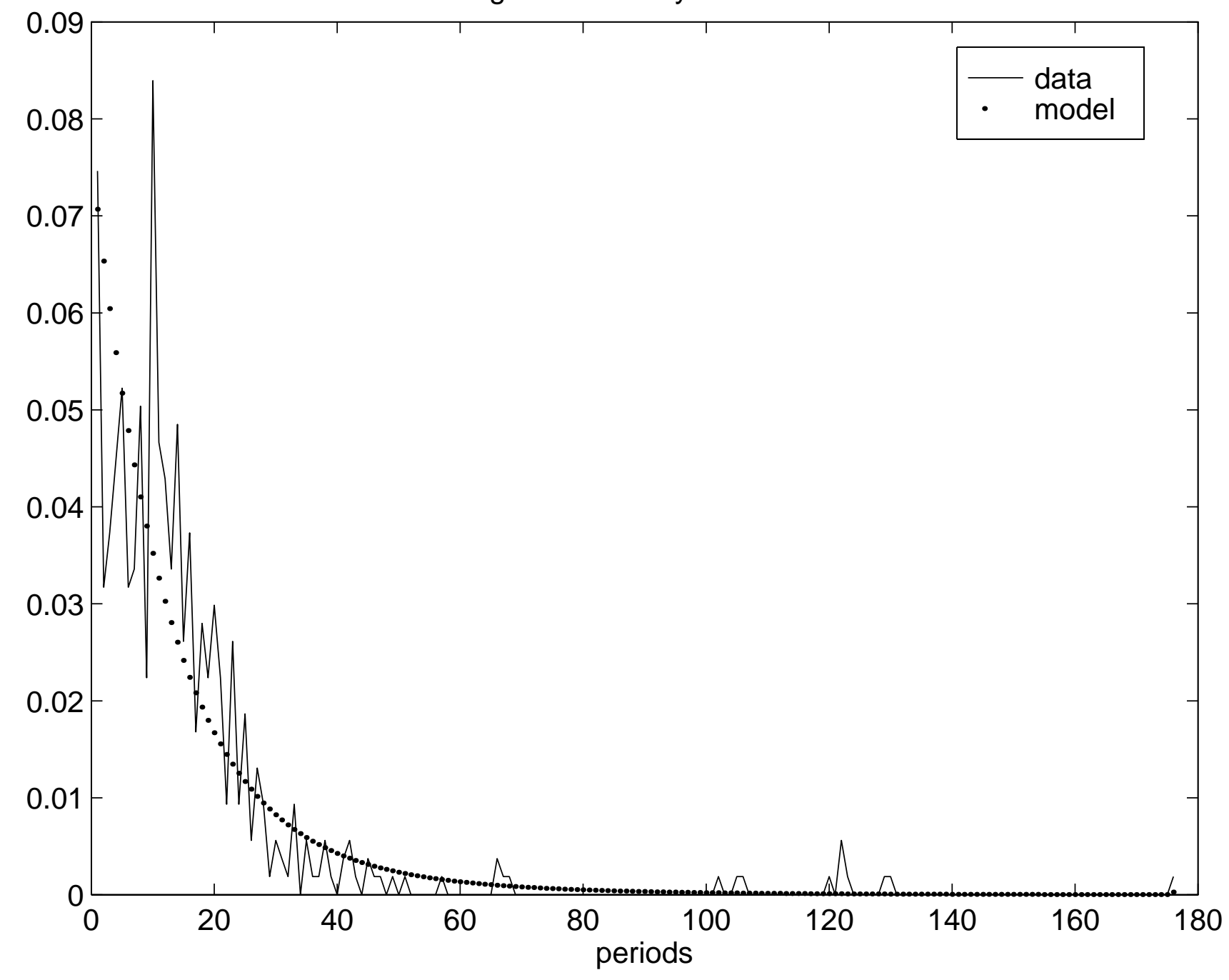


Figure 2: Distribution Functions for Sector 1

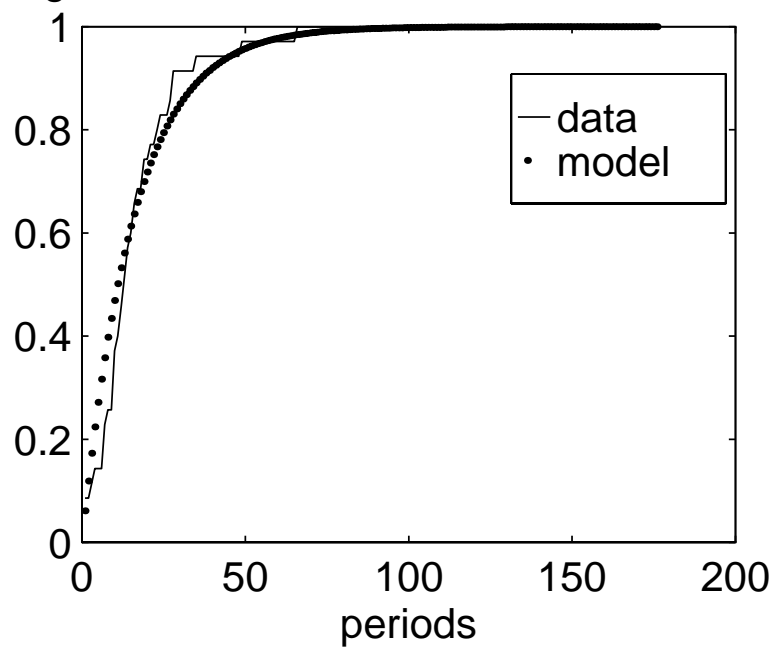

Figure 3: Distribution Functions for Sector 2

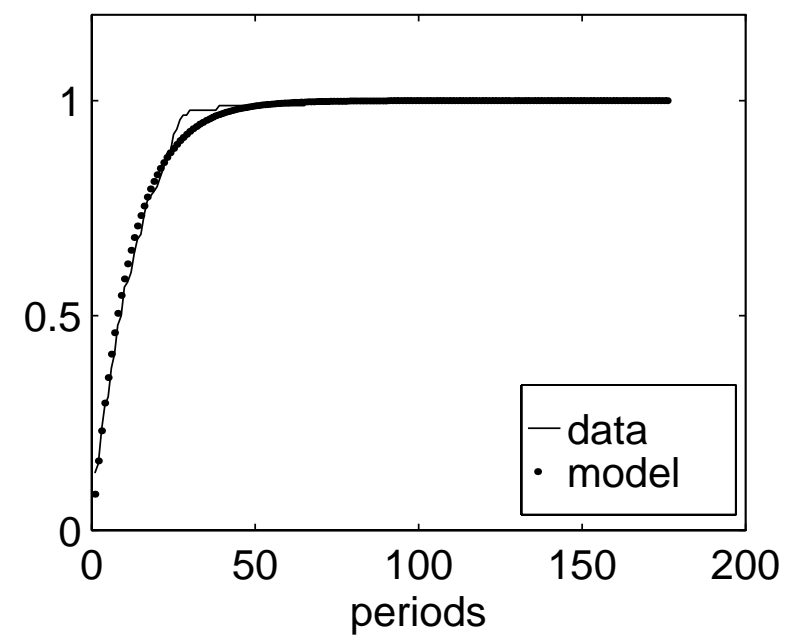

Figure 4: Distribution Functions for Sector 3

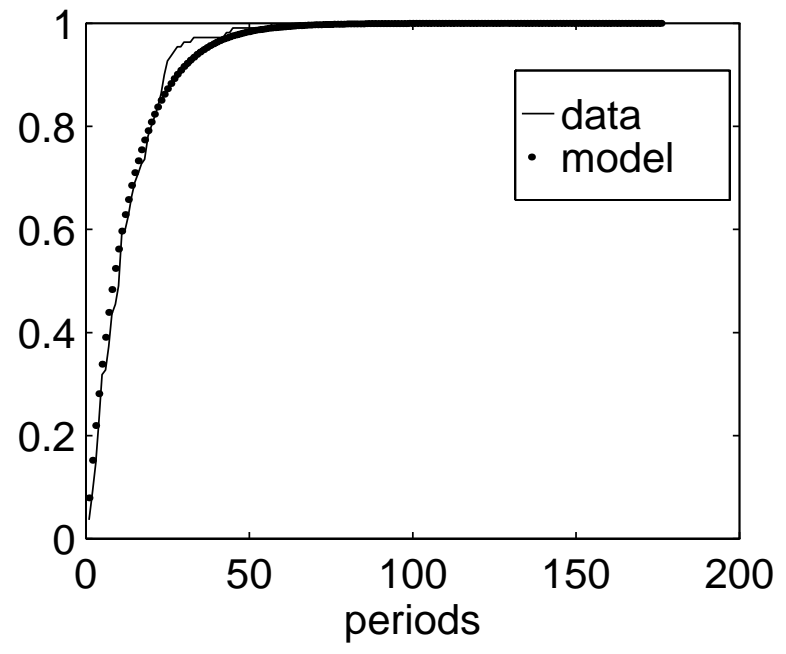


Figure 5: Distribution Functions for Sector 4

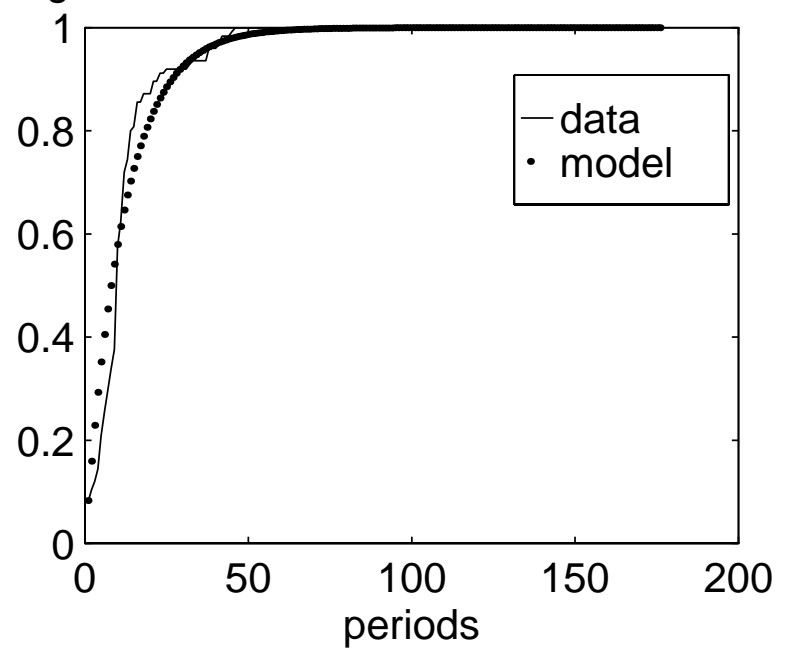

Figure 7: Distribution Functions for Sector 6

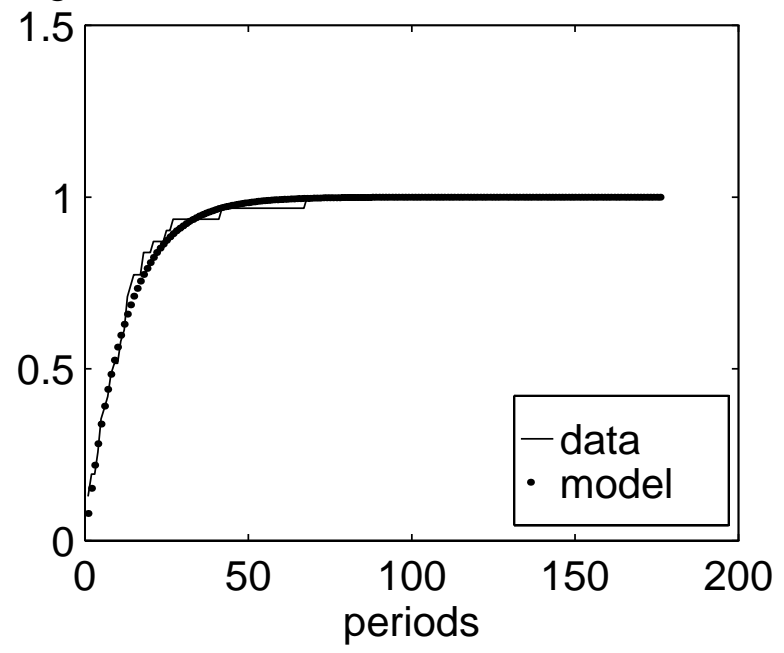

Figure 6: Distribution Functions for Sector 5

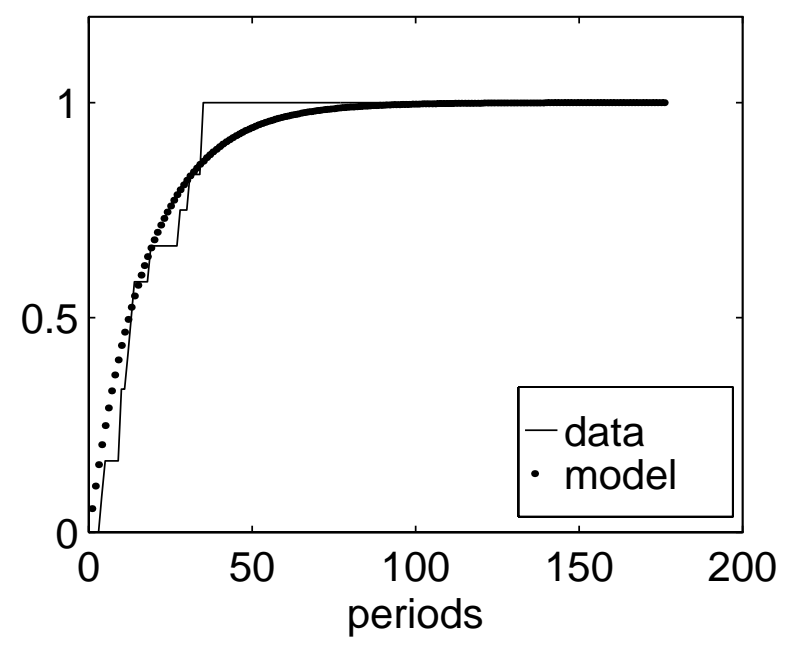


Figure 8: Distribution Functions for Sector 7

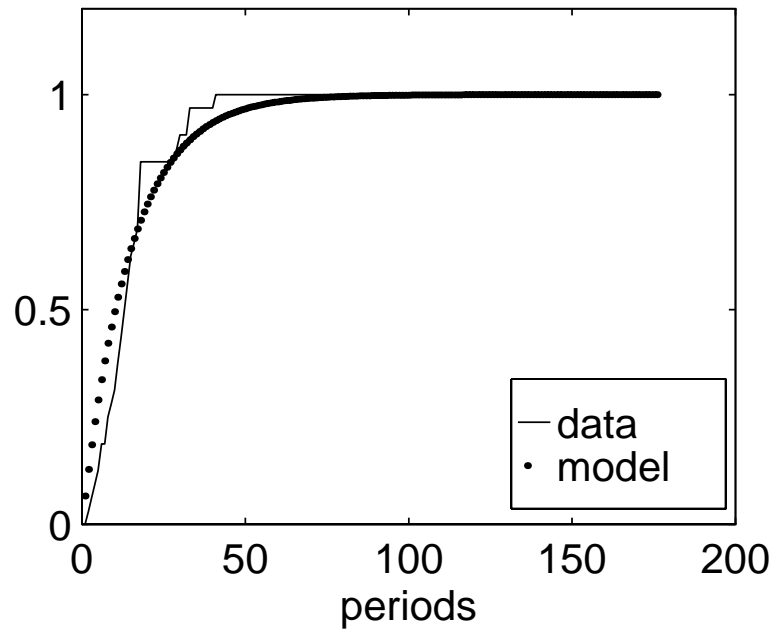

Figure 9: Distribution Functions for Sector 8

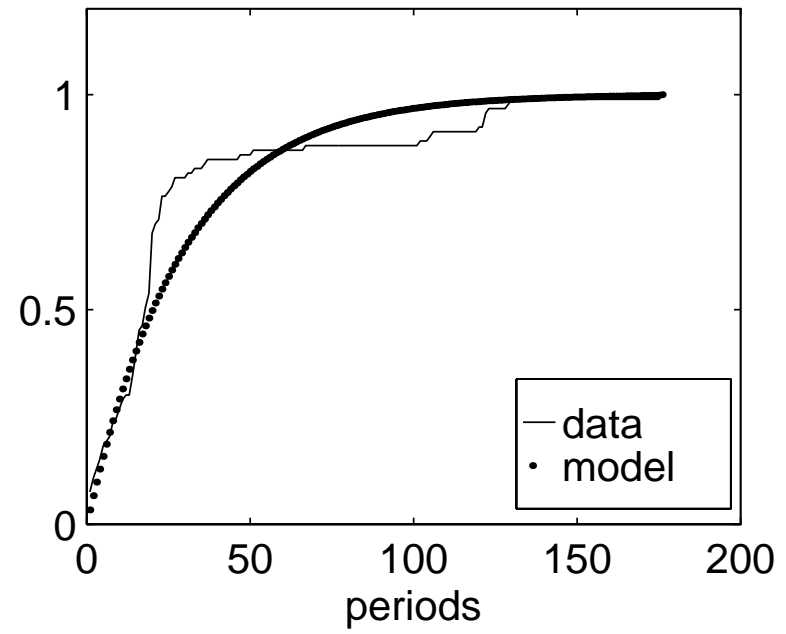

Figure 10: Distribution Functions for Sector 9

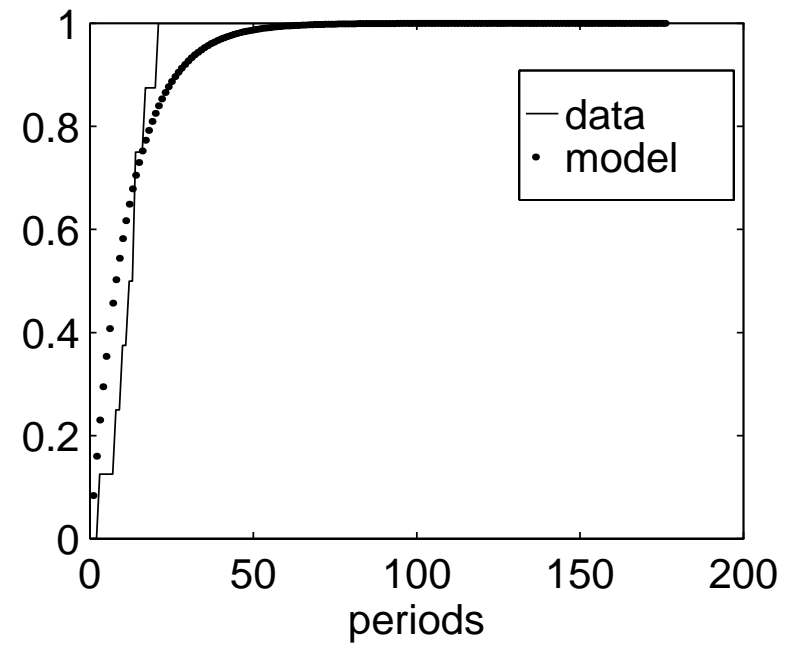

